\title{
RADON: GEOINFORMATION FOR THE PLANNING OF URBAN - SUBURBAN REGIONS. THE CASE OF NAFPLION CITY, GREECE
}

\author{
A. Koukoulis ${ }^{1}$ and D.E. Karageorgiou ${ }^{1}$ \\ ${ }^{1}$ Institute of Geology and Mineral Exploration, Olympic Village, Entrance C, 13677 Acharnae, Greece, \\ dek@igme.gr
}

\begin{abstract}
Radon is trapped in the terrestrial cover as a transmutation product of natural radioactive elements. It is directly related to the geotectonic environment and the atmosphere contains traces of radon near the ground, as a result of emanations from soil and rocks, both of which contain minute quantities of radium; it also infiltrates into the ground and circulates in groundwater. Because naturally occurring radon gas has come to be recognised as a potentially serious health hazard, especially in the built environment, a radon and radiometric ( $\alpha$-and $\gamma$-radiation) survey was carried out in the urban and suburban region of Nafplion, using the same grid of $500 \times 500 \mathrm{~m}$ that was used by other methods, i.e., urban geochemical and geophysical surveys. Radon was measured down to a soil depth of $50 \mathrm{~cm}$, and at each site $\alpha$-and $\gamma$-radiation measurements were taken. The survey results have shown that these concentrations are low compared to other regions of Greece. However, potential accumulations of radon in closed underground spaces cannot be excluded. The isoradon contours of these concentrations form anisotropy axes of main NW to NE and N-S direction related to geological-tectonic structures.
\end{abstract}

Key words: Radon, $\gamma$-radiation, $\alpha$-radiation, urban, Nafplion, Peloponnese, Greece

\section{Introduction}

It is well known that radon gas is widespread in the environment at low levels, however it can easily accumulate in closed underground spaces and with passive escape it can reach houses and endanger human health. Its short half-life allows radon to travel long distances, before its radioactivity decreases by half, rendering it a good indicator- tracer of deeper causes of the background, invisible from the surface (Vougioukalakis, et al., 2000), due to the fact that as a noble gas it does not participate in reactions.

The current study is performed in the context of a more integrated design involving the geological, geotechnical, hydrogeological, geochemical and geophysical research and study of urban and suburban pilot area of Nafplion in Argolida Prefecture. The measurement of radon at the depth of $50 \mathrm{~cm}$ is followed by the measurement of $\gamma$-radiation in the same position on the surface, in order to correlate the radioactivity of rocks with radon.

The radon concentrated in the soil depends on its high or not high production, on the rock background, or on its escape or not escape to the atmosphere. These mechanisms can change from one rock to another, or even in the same rock, therefore the study of radon in soil requires special attention to the geological - tectonic environment, as well as the general mechanisms of permeability, porosity, solubility in water, etc. 


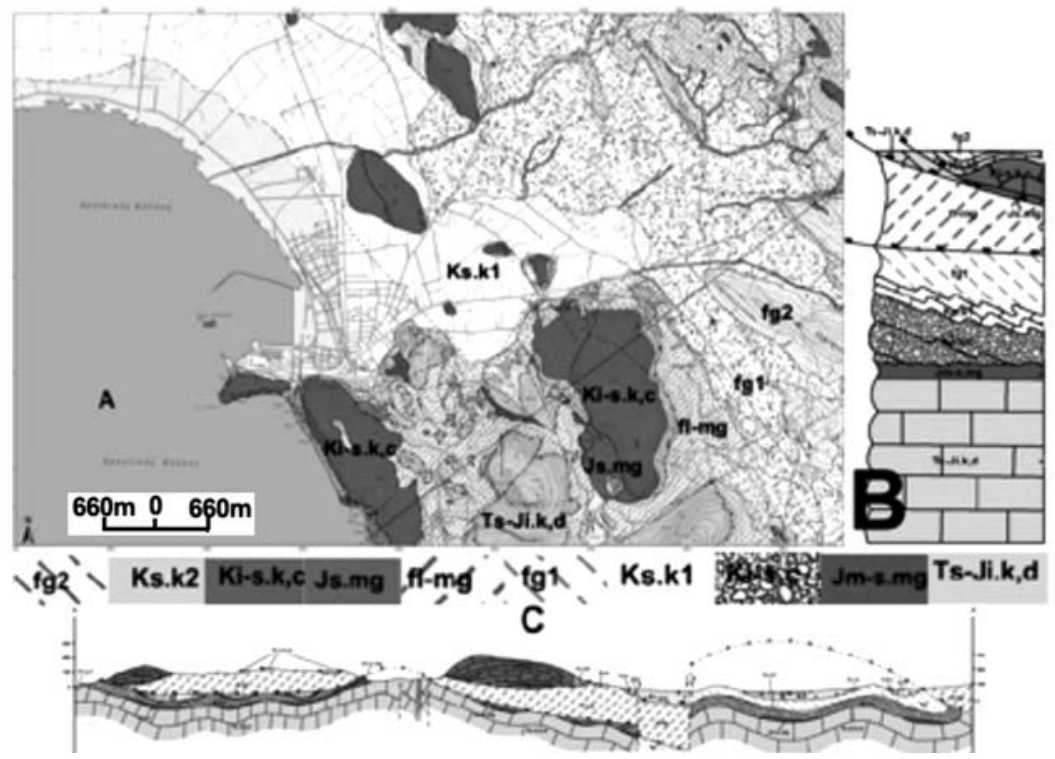

Fig. 1: Geological map (A), tectono-stratigraphic column (B) and geological section (C) of the greater Nafplion area. Lower Unit, Triassic-Jurassic shallow-water carbonate (Ts-Ji.k,d), tectono-sedimentary ophiolitic melange (Jm-s.mg), Meso-autochthonous series with Cretaceous carbonates (Ki-s.c \& Ks.k1), post-Ypresian flysch (fg1); Middle Unit, flyschoidal melange complex (fl-mg); Upper Unit, serpentinite sole (Js.mg), Triassic-Jurassic carbonate outlier (Ts-Ji.k,d),Cretaceous carbonate outlier (Ki-s.k,c \& Ks.k2) with flysch (fg2) and late Eocene tectonic phase. (Photiadis, 2010).

Upon processing the first data, specific distribution structures were already revealed, which demonstrate the sensitive behaviour of the method applied for the correlation of radon in soil with geotectonic structures in research area. A first interpretation of the sensitive variations is given with the geological map of research area on scale 1: 5,000.

\section{Geological Environment}

The geological structure of research area came from the tectonic accumulation of three units, after a series of compression and tensile events, which occurred generally in the Pelagonic zone from Jurassic until the post-Eocene period. It is distinguished (Photiadis, 2008) as follows:

The para-autochthonous or lower unity, of middle Triassic-Lias age consisting of a carbonate, neritic sequence with pelagic, nodular limestones, pelagic sediments of red cherts, siliceous silts and a tectonic-sedimentary mixture of Malm age. The carbonate conglomerate sequence of Cretaceous and the post-Ypresian flysch of Argolida follow unconformably after several erosion and emersion events.

The intermediate unit, of post-Eocene occurring through a flyschoid tectonic mixture of continental and oceanic tectonic bodies into a flyschoid cementing material due to the collapse, destruction, detachment and tectonic accumulation of the internal pelagonian - continental margin during the collision of the Hellenides.

The upper section, which is tectonically drifted with (or without) intercalation of the previous unit, 
consisting of limestone flakes of Cretaceous age with accompanying tectonic foot of serpentinites, as well as mega-blocks of carbonate rocks of middle Triassic-Lias age, detached from the underlying lower unit.

\section{Methods}

\subsection{Measurement Instruments}

Measurements of radon in soil of urban and suburban areas Nafplion, initially started with the use of two instruments: RAD 7 by Durridge (USA) and EPP 10 by Saphymo - Stel company (France). Both are portable units designed to measure radon in air sample in soil. RAD 7 is a monitoring, sensitive and automated instrument, but has a significant turnaround time, of about $1 \mathrm{~h}$. The instruments' measurement is taken in automatically controlled humidity, which must be less than 5\%. The electronic detector of moisture blocks often rendering the instrument difficult to handle for systematic research. The instrument has a silicon detector. The measurements are repeated in 4 equal time intervals and are given in pci/l with a deviation of a few tens of units. Printed histograms of the radioactive element that emits radiation are given too. EPP 10 is not a recording - automatic instrument, but it is suitable for systematic work and, more importantly, it does not block outside. For the above reasons, after a series of double measurements and due to the fact that significant problems were encountered with the electronic instrument, the measurements were limited to EPP 10.

The scintillation- meter consists of a 150 AVP photomultiplier, which transforms into electricity the sparks emitted by ray alpha upon hitting the inner walls of glass vial coated with zinc sulphide and activated with silver $(\mathrm{ZnS}[\mathrm{Ag}])$. These electrical impulses then determine the electronic circuits of information processing, from which finally a micro amber meter gives results expressed in beats per second, c / s, (Dumoulin, 1978).

The measurement of $\gamma$-radiation at ground level is fast becoming a routine using the Saphymo - Stel company (France), SPP2N meter of scintillation for small, intermediate and large scales of measurements, 50, 150, 500, 1,500, 5,000 and $15,000 \mathrm{c} / \mathrm{s}$. A NaI crystal is built into the portable device and the measurement refers primarily to the $\gamma$-radiation emitted by radio with the farther degradations elements lead and bismuth 214 with a small half period of 26.8 and 19.7 minutes, but with the relevant energy being at the highest level of $0.188-(0.250-0.294-0.350)$ and $0.606 \mathrm{MeV}$ respectively.

The measurement of gamma radiation is proportional to the quantity of the parent uranium, as long as there was enough time to reach radioactive equilibrium, 1 million years for the group of uranium and 70 years for that of thorium. Usually the radioactive equilibrium exists in nature, but sometimes

Table 1. Average calculated correspondence for different units in four (4) representative radon value groups in Nafplion area.

\begin{tabular}{|c|c|c|c|}
\hline Class c/s EPP 10 & pci/lt & $\mathbf{B q} / \mathbf{m 3}$ & \% Prices \\
\hline $0,0-1,0$ & $0,0-27,4$ & $0,0-1.015$ & 47,47 \\
\hline $1,0-3,0$ & $27,4-82,2$ & $1.015-3.045$ & 27,85 \\
\hline $3,0-4,5$ & $82,2-123,4$ & $3.045-4.570$ & 9,49 \\
\hline$>4,5$ & $>123,4$ & $>4.570$ & 15,19 \\
\hline Total & & & 100 \\
\hline
\end{tabular}


there is movement, solubility, leaching or precipitation of one element and as a result some already existing elements, for example in water, are found in abundance and other insoluble elements will be deposited because of their nature. In this case, a full analysis of radioisotopes, which can be identified, such as uranium, thorium, radium, radon, etc. (CREGU, 1981) is necessary.

\subsection{Field research measurements}

Based on the research needs of the project, the measurements in the field were carried out using grid of $500 \mathrm{~m}$. The identification of the location spots in the countryside was determined with GPS of a few meters' accuracy, in relation to fixed points such as roads' intersections, canals, streams, etc., as well as morphological data of the area. The approach of the desired point was achieved either by car or on foot, while in case this was difficult or impossible; the closest accessible spot to the location was selected, in order to increase productive work time.

Before air sampling, from a depth of about $50 \mathrm{~cm}$ in the ground, the instrument was prepared, vacuum was created inside, the indications were controlled etc. In the first five minutes of operation of the instrument, which is the accepted constant of integration, the average price represents the best measurement of the position.

For a total research area of about $36 \mathrm{Km}^{2}, 158$ measurements were taken, which are, prima facie, satisfactory for the identification of sensitive variations of radon, i.e. approximately 5 measurements per $\mathrm{Km}^{2}$.

\section{Results - Assessment}

The summary of data measurements is presented in Tab. 2 and Table 3, expressed in c / s, SPP2N and EPP 10, for the $\gamma$ and $\alpha$ radiations of stations of the research field.

In an ideal case, the values of radon in soil should remain at stable levels. However, in most cases radon prices often vary, due to various factors, such as changes in the uranium-thorium contents in different background rocks, or even in one and the same rock, variations to thickness, porosity, per-

Table 2. Data of $\gamma$ radiation in the urban and suburban area of Nafplion.

\begin{tabular}{|c|c|c|c|c|c|}
\hline $\begin{array}{c}\text { Serial } \\
\text { Number }\end{array}$ & Class & Mean class & Frequency & $\begin{array}{c}\text { Cumulative } \\
\text { Frequency }\end{array}$ & \% Prices \\
\hline 1 & $0,0-5,0$ & 2,5 & 0 & 0 & \\
\hline 2 & $5,0-10,0$ & 7,5 & 9 & 9 & 25.95 \\
\hline 3 & $10,0-15,0$ & 12,5 & 23 & 32 & \\
\hline 4 & $15,0-20,0$ & 17,5 & 24 & 56 & \\
\hline 5 & $20,0-25,0$ & 22,5 & 37 & 93 & 46.20 \\
\hline 6 & $25,0-30,0$ & 27,5 & 12 & 105 & \\
\hline 7 & $30,0-35,0$ & 32,5 & 16 & 121 & \\
\hline 8 & $35,0-40,0$ & 37,5 & 20 & 141 & 22,78 \\
\hline 9 & $40,0-45,0$ & 42,5 & 5 & 146 & \\
\hline 10 & $45,0-50,0$ & 47,5 & 11 & 157 & 10,76 \\
\hline 11 & $50,0-55,0$ & 52,5 & 1 & 158 & \\
\hline
\end{tabular}


Table 3. Radon subsoil in urban and suburban area of Nafplion.

\begin{tabular}{|c|c|c|c|c|c|}
\hline $\begin{array}{c}\text { Serial } \\
\text { Number }\end{array}$ & Class & Mean class & Frequency & $\begin{array}{l}\text { Cumulative } \\
\text { Frequency }\end{array}$ & $\%$ Prices \\
\hline 1 & $0-0.5$ & 0.25 & 63 & 63 & 47.47 \\
\hline 2 & $0.5-1.0$ & 0.75 & 12 & 75 & \\
\hline 3 & $1.0-1.5$ & 1.25 & 9 & 84 & \\
\hline 4 & $1.5-2.0$ & 1.75 & 12 & 96 & \\
\hline 5 & $2.0-2.5$ & 2.25 & 12 & 108 & 27.85 \\
\hline 6 & $2.5-3.0$ & 2.75 & 11 & 119 & \\
\hline 7 & $3.0-3.5$ & 3.25 & 10 & 129 & \\
\hline 8 & $3.5-4.0$ & 3.75 & 4 & 133 & 9.49 \\
\hline 9 & $4.0-4.5$ & 4.25 & 1 & 134 & \\
\hline 10 & $4.5-5.0$ & 4.75 & 6 & 140 & \\
\hline 11 & $5.0-5.5$ & 5.25 & 5 & 145 & \\
\hline 12 & $5.5-6.0$ & 5.75 & 5 & 150 & \\
\hline 13 & $6.0-6.5$ & 6.25 & 4 & 154 & \\
\hline 14 & $6.5-7.0$ & 6.75 & 2 & 156 & 15.19 \\
\hline 15 & $7.0-7.5$ & 7.25 & 0 & 156 & \\
\hline 16 & $7.5-8.0$ & 7.75 & 0 & 156 & \\
\hline 17 & $8.0-8.5$ & 8.25 & 1 & 157 & \\
\hline 18 & $8.5-9.0$ & 8.75 & 0 & 157 & \\
\hline 19 & $9.0-9.5$ & 9.25 & 0 & 157 & \\
\hline 20 & $9.5-10.0$ & 9.75 & 1 & 158 & \\
\hline TOTAL & & & & & 100 \\
\hline
\end{tabular}

meability, the circulation of hot or cold water, or some changes from cracks, joints, etc., allowing dissolution in water or passive removal - release of radon into the atmosphere.

According to the measurements from all plants (Table 3):

- 47\% of the data indicates very low values of 0,0 - 1,0 c / s EPP 10, namely 0,0 - 27,4 pci / lt or $0,0-1.000 \mathrm{~Bq} / \mathrm{m}^{3}$,

$-28 \%$ of the values also remains lower than $1,0-3.0$ ERP 10 , namely $27,4-82,2 \mathrm{pci} / \mathrm{lt}$ or $1.000-3.050 \mathrm{~Bq} / \mathrm{m}^{3}$,

$-25 \%$ of the values is higher than $3.050 \mathrm{~Bq} / \mathrm{m} 3$, although they are still lower than the values of radon in other regions of Greece.

As a measure of comparison it should be mentioned that in France, 200 - $500 \mathrm{~Bq} / \mathrm{m} 3$ are accumulated in closed spaces, when values greater than $10.000 \mathrm{~Bq} / \mathrm{m} 3$ are measured in the underground (Lempereur, 1988). Also in the urban area of Kalamata, in all 370 radiotracer open- type LR 115 in schools and underground spaces, almost all values of radon were below the level of $200 \mathrm{~Bq} / \mathrm{m} 3$ (Geranios et al., 2001). 




Fig.2: Distribution of $\gamma$-radiation in urban and suburban area of Nafplion.

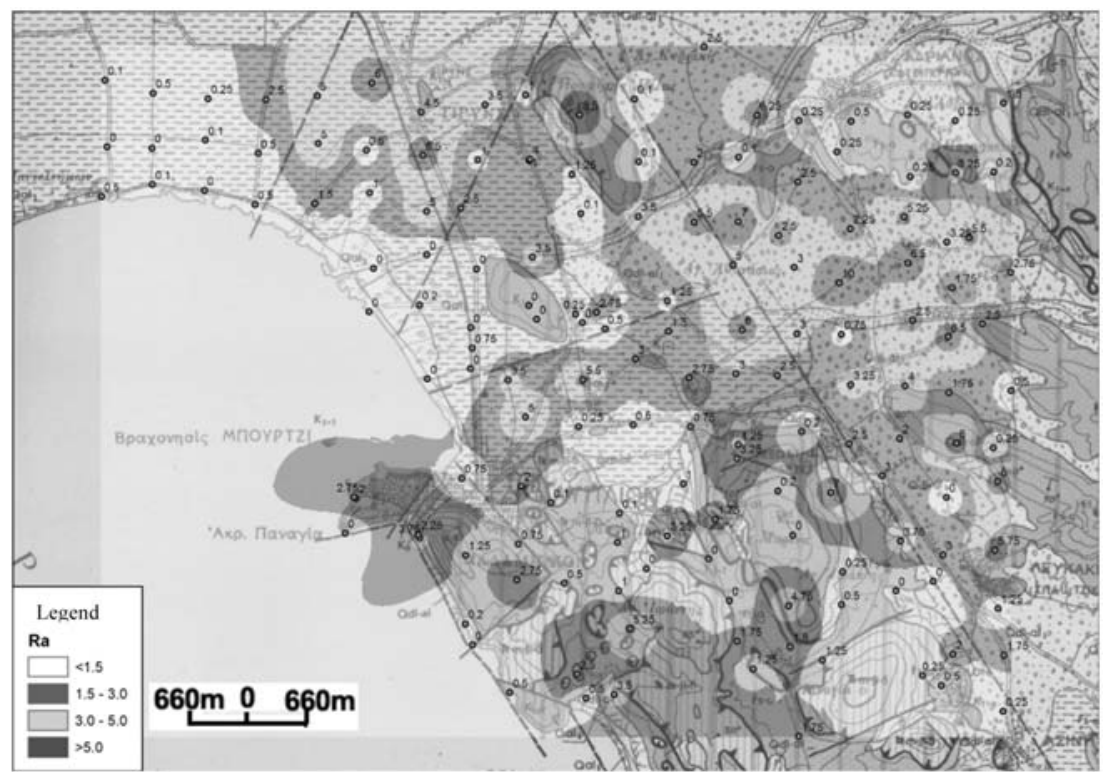

Fig 3: Points of measurements of radon and uranium in the urban and suburban area of Nafplion.

For the overall assessment of risk from radon in the human environment three key parameters are necessary to evaluate: the contents produced by the background rock, the selective-passive escape of radon in the air and the potential accumulation in enclosed and thus habitable spaces. Therefore, the measurement of radon in soil expresses the result of the first two factors. 
The level of measurement of radon is affected significantly by water, since radon has a large solubility in water depending also on its physiochemical characteristics such as $\mathrm{pH}$, temperature, pressure, concentrations of various ions, metals, non-metals compounds, etc. It is soluble in certain circumstances and less in others, for example at $0^{\circ} \mathrm{C}$ exhibits the double rate of solubility in comparison with the 25o C (Ball et al., 1991).

Given the above, the values of radon stand out in the old and new deposits of streams, north-east of the outskirts of Nafplion, which exhibit a high background with most of the highest rates of radon above the $X+2 \sigma$.

Low concentrations are present in the Cretaceous limestones, in contrast to those of Senonion, where two stations measured amongst the highest concentrations.

Interim radon values, with the greater range, from very low values to well above $X+\sigma$ are present in the flysch. The same prices are presented in alluvial deposits in the area of St. Panteleimon.

Tiryntha and Nafplion. In these cases, however, the values form North - East axes anisotropy near the town of Nafplion and in North - South direction close to Tiryntha, associated with non-visible from the surface geotectonic structures.

However, the main anisotropy in the distribution of radon, which is almost parallel to the coastline and is about $3 \mathrm{Km}$ from this, found at the level of the town of Nafplion up to $1 \mathrm{Km}$ of the level of Tiryntha, appears to have a northwest direction. It extends across virtually all geological formations with a thickness exceeding the $2 \mathrm{Km}$ and is associated with deeper tectonic structures invisible on the surface, but also on the geological occurrences under study.

The average Triassic limestone for example, or those of the lower Cretaceous and flysch appear to eliminate the impression of these deep structures, southeastern of Nafplion town, in relation to existing deposits in North -East .

An interruption or also cover of the mega-structure in North - West appears at the area of Prophet Elias of Nafplion and Tiryns, having a North -East direction and a smaller North-South direction respectively with reduced radon values, which could be interpreted as a possible definition of the entry area of the sea to the well horizon.

\section{Conclusions}

The concentrations of radon in urban and suburban area of Nafplion, which are measured on the ground, do not represent a source of additional radioactive burden for the population. These values, like the values of $\gamma$-radiation at ground level are low compared with other regions of Greece. As low as they may be, potentially, one cannot exclude the possibility of radon accumulation in enclosed underground spaces to levels that require check of the house for the existence of radon.

The isoradon curves show anisotropy axes, which vary according to the geological formation and the underlying deeper or not tectonic structures, prevailing in the area of research. Three issues can be identified:

1) Separation of rocks with the lowest, intermediate and above the level $X+2 \sigma$ concentrations.

2) A dominant anisotropy Northwest, almost parallel to the coastline, which is associated with underlying tectonic structures and shows a slight growth of her conjugate at North- East direction, at the level of Nafplion town. 
3) Smaller North- East and North - South anisotropies at the height of Prophet Elias Nafplion area and Tiryntha respectively, may designate the possible range of sea entrance shaft to the well horizon.

\section{Acknowledgments}

For the integration of Radon research to the project "Geological research of urban and suburban areas of Greece", and the excellent cooperation, we would like to thank sincerely all the staff of the project and principally the Project Leader Mr. P. Tsompos. Also sincere thanks to our colleague M. Xenakis for his assistance on mapping system with GIS and finally to Barbara Pefani for her remarks in the presentation of this study.

\section{References}

Ball, T. K., Cameron, D. C., Colman, T. B., Roberts, P. D., 1991. Behaviour of radon in the geological environment; a review. Quart. J. Engin. Geol., 24, 169-182.

CREGU, (Center for Research on the geology of uranium), 1981. Uranium and oxido-reduction, Nancy, CREGU, 316 pp.

Dumoulin, C, J., 1978. Methods of detection of uranium, Razes, Center for Information and specificity, CEA, $141 \mathrm{p}$.

Geranios, A., Kakoulidou, M., Mavroidis, F., Moschou, M., Fischer, S., Burian, I. and Holecek, J., 2001. Measurements of radon in Kalamata, Greece, NCSR Demokritos * *, 1st Congress of Environmental Radioactivity ".", 41 - 44 p.

Lempereur, J, D., 1988. A deadly gas blowing from the subsoil, France, Science and Life, no 846,11 pp.

Photiadis, A., 2008. Geological study of urban and suburban pilot area Nafplion, IGME, 15 p.

Photiadis, A., 2010 Geological survey in scale 1:5.000 of the greater Nafplion area (NW Argolis, Greece)

Vougioukalakis, G., Vlachos, M., and Kaliotzis, G., 2000. Soil gas measurements in Attica during the earthquake of September 1999, Athens, IGME, 8 p. 